\title{
Assessing varied instructional approaches in the instruction of online graduate students
}

\author{
Mary Francis
}

\begin{abstract}
Distance learners, and in particular distance graduate students, can be a neglected portion of the student body; however, the library needs for this growing student group are real and important. This paper explores an Association of College and Research Libraries (ACRL) Assessment in Action: Academic Library and Student Success project which examined two different instructional methods offered to students in an online graduate education programme. Specifically, the study assessed the effect of an online tutorial and individual contact with a librarian. The tutorial showed a statistical difference between pre- and post-test results. The limited number of students participating in the individual contact did not allow for the establishment of statistical difference, but the study did provide evidence on how to improve the current reference system.
\end{abstract}

\section{Introduction}

Graduate students taking online courses leading to a Master's degree can be a neglected subset of library patrons as they are often a small percentage of the total student body. Their lack of physical presence on campus also means they are easily overlooked; however, their library needs are real and important. Having successfully completed an undergraduate degree and been accepted into a graduate programme does not necessarily indicate that graduate students have mastered the skills required to find, use, and evaluate information. In addition to the basic research skills required by these students, they also face new challenges as they are expected to move beyond the undergraduate research paper which often relied on analysis of other articles, to conducting their own original research. This requires a new set of skills and knowledge about information, all of which must be learned. A number of studies have shown a lack of research skills by graduate students (Barrett, 2005; Catalano, 2010; Chu and Law, 2007; Green and

\section{Author}

Mary Francis is Reference Instruction Librarian at Dakota State University, South Dakota, USA. She is an Assistant Professor.

Email: mary.francis@dsu.edu

Received 28 August 2014

Accepted 09 November 2014 
Macauley, 2007; Switzer and Perdue, 2011). In addition to this difficulty faced by many students registered for online graduate courses is the fact that these individuals may experience a psychological distance from the library. Sometimes distance students fail to appreciate the full breadth of library services available to them, as they have come to expect limited resources compared to on-campus students in their dealings with other student support services (Kayongo and Helm, 2010 and George et al., 2006).

This deficiency in research skills on the part of their graduate students was noticed by librarians and faculty members supporting the MA in Education programme at a small, public university. To address this problem, two faculty members with a librarian took part as a team in the ACRL's Assessment in Action: Academic Libraries and Student Success programme. The first year of this programme was made up of teams from 75 institutions, which worked on individual assessment projects at their specific institutions. These projects covered a wide range of student support programmes run by library and information services, such as an end of the semester all-night open house for walk-in library users offered to all levels of students from freshman to graduate students. Librarian team leaders worked as a cohort to establish a learning community through an online forum, face-to-face meetings, and several webinars. This fifteen-month programme provided "librarian team leaders $[. .$.$] the freedom to$ connect, risk, and learn together" (Association of College and Research Libraries, 2014). While each librarian focused on the results of their individual projects during the programme, with the end of the structured programme, it would be possible to look at the cumulative effect of these projects on student success.

The courses assessed within this study are required within the MS in Educational Technology. This programme requires 36 credit hours composed of 25 required credit hours and 11 hours of electives. Due to the needs and requirements within the two courses taught by the faculty members, different instructional approaches were used. Within the course LT 785 Research Methods in Educational Technology, students were provided with an online tutorial of videos and readings and were assessed with a pre/post-test as well as a research process worksheet. In the course LT 741 Introduction to Distance Education, students were instructed to individually contact a librarian to discuss the appropriateness of an article for a graduate level course. They were assessed on the quality of their final position paper.

Within academic libraries, much of the traditional focus of information literacy has revolved around the instruction offered to undergraduates during face-to-face training sessions. Thus, most of the literature also focuses on assessment of undergraduate instruction. Research articles taking smaller subsets of students for analysis are only gradually becoming more common. One subset which has increased due to the continual expansion of distance education is online students, as librarians explore how to reach, serve, and assess the work they do for these individuals. Another subset of students evaluated in the literature is graduate students. This paper will join these two student subsets to discuss an assessment 
project that explored two different instructional approaches taken to reach graduate students in online courses within an Education degree programme.

\section{Literature Review}

Studies examining user needs of online students in relation to library services have taken a variety of approaches. Some have considered the different services libraries are offering to distance students in an attempt to meet the ACRL's Standards for Distance Learning Library Services which states that members of the distance learning community must be provided with "equivalent" services and resources as those provided to students in the traditional campus setting (American Library Association, 2008). Others have looked at library use by distance students including services used, preferences, and attitudes. These have primarily been self-reported surveys in which students report on their experiences. These surveys also attempt to rank the importance of various library services for online students (Hensley and Miller, 2010).

Another subset of research on online students considered the effectiveness of online instruction. Numerous studies have found that online instruction is as effective as face-to-face instruction as seen in the research analysis conducted by Zhang, Watson and Banfield (2007). While many of these studies focused on undergraduate students, Shaffer looked at online instruction for graduate students. Her findings also showed no statistical difference in the learning that took place between online and face-to-face instruction, although in her study the face-to-face students did report more satisfaction with the instruction (Shaffer, 2011).

Research on graduate students and their requirements concerning library services have explored a variety of issues. Some consider the space, service, and research needs of the students (Gibbs et al., 2012; Rempel et al., 2011; Ismail, 2013). Others consider the research practice of students by discovering where and how they search for information (Kayongo and Helm, 2010; Blummer, Watulak and Kenton, 2012; Catalano, 2013). Some have looked at the students' self-perception of their research skills (Catalano, 2010). Blummer (2009) provides a literature review of the content, goals, and objectives of instruction offered to graduate students from the 1950s through the early 2000s.

An article of particular interest to this study describes a proposed library training unit for Education Graduate Students at Towson University (Blummer, Kenton and Liyan, 2010). The authors note how the research needs of various disciplines vary, so in order to provide the best instruction it is important to tailor the topics and methods for the students. While the article provides an outline for library instruction, it does not report on the assessment results.

\section{Methodology}

The information needs of graduate students can be varied and complex. This was no different for the two courses that were part of this assessment (Dakota State University, 2015). They each required students to use information in different 
ways and to meet these needs, two different instructional methods were used. This variety within instruction method also speaks to the idea that:

offering training in a variety of formats (e.g. one-on-one consultations, one-shot classes, workshops, online learning) at different events during a graduate student's coursework can address the needs of different learners.

(Catalano, 2013, 269)

The first course (LT 785) was focused on research methods and was intended to prepare students to be critical consumers of research within the education field. The library instruction unit focused on the general research process including:

- search techniques;

- locating resources;

- evaluating;

- using the information.

This material was covered through a self-paced, online tutorial composed of videos and readings. Students were assessed through a pre/post-test and a research process worksheet which was completed during the tutorial. In addition to collecting the worksheet, the students also completed a multiple choice quiz based upon their responses to the worksheet.

While not quite self-paced, this course allowed students to move through the material individually. The course was composed of a variety of units, with one unit opened per week within the Course Management System and the students were given three weeks to work on the content. The library unit had to be completed in steps with each section opening after the one before was completed. First, the students completed the pre-test. Second, they went through the online tutorial and completed the research process worksheet. Third, they completed a research process quiz based on their answers to the worksheet. Finally, they completed the post-test to end the unit. The librarian was given full access to the online course to view the progress of the students as well as answer any questions on the process or content.

The second course (LT 741) covered distance learning and required the students to write a position paper as well as to review research articles. To aid the students in their search for resources, they were instructed to contact the librarian with an article they had found in order to discuss its reliability and quality. As these students were online, they were provided with an email address for a librarian to contact. The students were assessed on the grade they received for their position paper. The scores earned by a past course on this assignment were used as a baseline for comparison.

\section{Findings}

There were 31 students in LT 785 all of whom completed the entire library unit. Students were asked to report on how long it took them to complete the online 
tutorial. Time ranged from 25 minutes to 300 minutes with an average of 111 minutes to go through the tutorial. The pre-test had 21 questions. The average score was 16.13 with the lowest score of 10 and the highest of 20 out of a possible 21 . The post-test contained the same 21 questions. The average score was 18.1 with the lowest score of 14 and the highest of 20. The research process worksheet quiz had 18 questions. Students earned an average score of 13.52 with the lowest score of 7 and the highest of 18 out of a possible 18. The pre/post-test score percentages are shown in Figure 1.

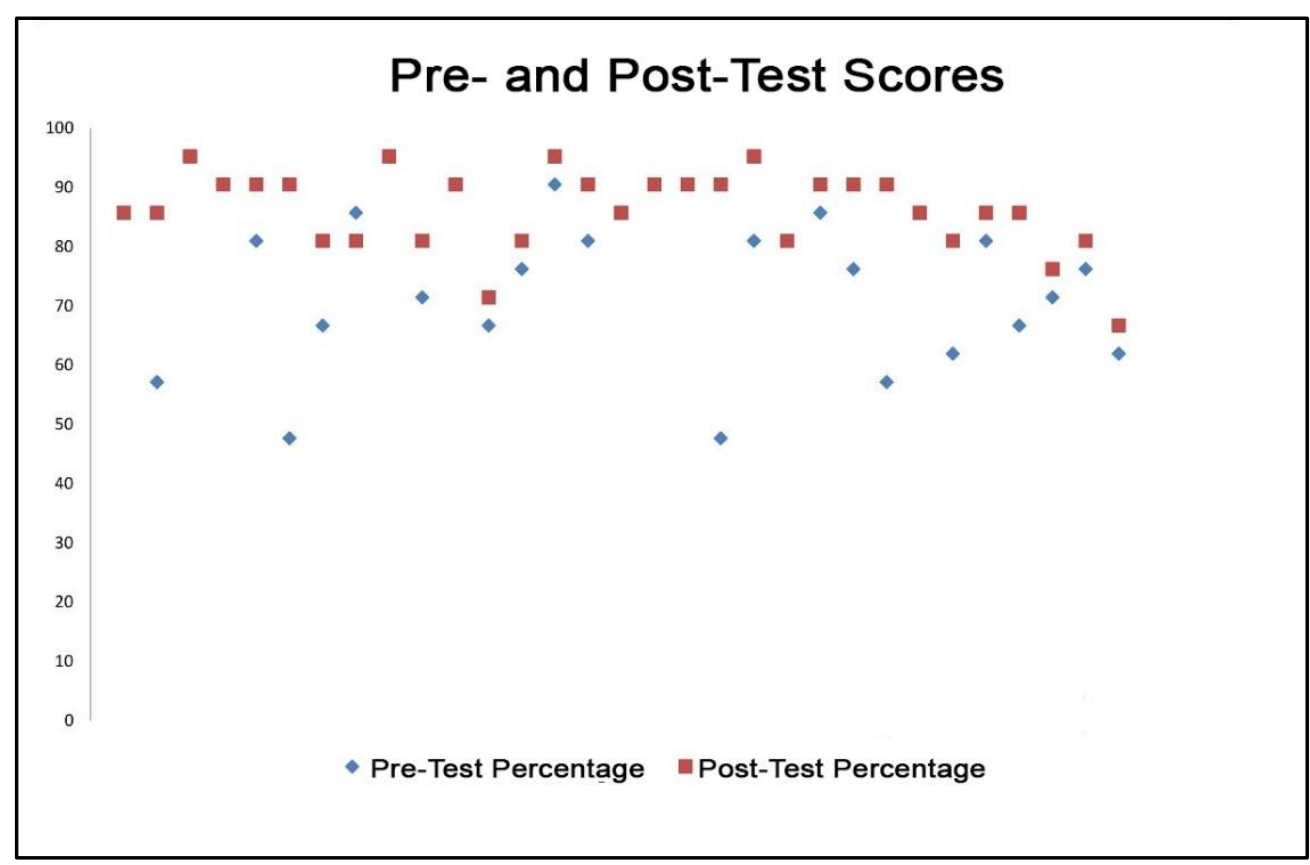

Figure 1: Individual results of pre and post-test. P-value $<.01$.

The scores for their pre-test, research process quiz, post-test, and the self-reported time to complete the online tutorial were all entered into the SAS statistical tool to determine if there was any correlation between the scores. Tests showed no correlation between the pre-test scores and research process quiz or time to complete the tutorial, or between the research process quiz and post-test or time to complete the tutorial, or between the post-test and time to complete the tutorial. A paired T-test was run looking at the scores of the pre- and post-test. The tests rejected the null hypothesis that there was no statistical difference in the scores. The p-value was less than .01 showing a significant statistical difference.

There were 8 students within the LT 741 course. They were all required to contact the librarian at least once. All of the students contacted the librarian through email. These students contacted the librarian an average of 3 times throughout the course. The most number of contacts with a librarian was 7 and the least number of contacts was 1 . There was also one student who came to the library to ask questions of the librarian in person. The average score on the position paper for these students was $90.63 \%$. These ranged from $80 \%$ to $100 \%$. These scores can be considered in comparison to the students in a previous class who did not interact 
with a librarian. The average position paper score for these students was $88.44 \%$ with a range from $70 \%$ to $97 \%$. Due to the low number of students, it was not possible to determine if there was a statistical significance in the difference of the scores.

\section{Discussion}

The results of the paired T-test on the pre- and post-test show that the students had learning gains during the library unit of their class. Of the 31 students, 30 either maintained or increased their post-test score over the pre-test. The fact that none of the other variables showed any correlation was not surprising. For instance, time taken to complete the tutorial varied widely in relation to the scores on the pre-test, worksheet quiz, and post-test. This could be due to a number of factors. Students who scored high on these assessments may have been thorough and spent a lot of time going through the tutorial or they may have already known much of the content and thereby gone through the tutorial quickly. Students who scored low on these assessments may have not spent time on the tutorial thinking it was not important or they may have had very little knowledge of the content and spent a long time on the tutorial. With all of these variables in students' prior knowledge, motivation, and skill, the fact that time spent on the tutorial did not correlate to the other variables is predictable.

When analysing the articles sent to the librarian via email by the students, several topics emerged that resulted in instructional opportunities related to evaluation. The first was related to currency. There were a number of submitted articles that were quite dated even though one requirement given by the professor was that the article be written within the last five years. When this occurred, the librarian sent a message back to the student noting how there were constant changes occurring within distance education, and it was important to use the most recent articles. Currency was also addressed in articles that were published recently, but reported on data that had been collected prior to the five year date. This prompted a suggestion by the librarian to encourage the students to look deeper into the article itself rather than simply relying on the citation date thereby promoting advanced evaluation.

Almost all the email exchanges included a discussion on the importance of peerreview. Those students who submitted an article from a peer-reviewed journal were reinforced in their choice with a comment on how peer-review is a method to help ensure the quality of a research article. Those students who did not submit a peer-reviewed article were given more information on the peer-review process and given suggestions on how to find such an article within the databases.

Another common element in the email exchanges was a discussion on topic choice for the final position paper. Students often needed to narrow their topic and the librarian provided some suggestions on how to focus within their larger issue.

The librarian spent between 15 and 40 minutes replying to each individual email. This time was spent reviewing and evaluating the submitted article and composing a response. Due to the small number of students within the course, this 
did not impose much additional work on the librarian. However, as much of the feedback was similar, in the future the students may receive some instruction prior to submitting their articles on the criteria they should address. This would decrease the librarian's workload by providing a rationale for evaluating the quality of the articles. Future iterations may ask the students to provide an evaluation of the article as well as the article itself. This would allow the librarian and faculty member to get a clearer picture of the students' knowledge.

In working on this project, it was important to have a good working relationship with the faculty members. At the most basic, this was required to establish any type of assessment as it was the faculty who assigned the student work, provided grades and allowed access to the course management system. Faculty support is also important as "faculty advisors play a dominant role in disseminating library research information to their students" (Catalano, 2013, 244). It is often only through the faculty member that online students have any introduction to the university library. Without encouragement or sometimes requirement to consult authoritative resources available through the library, students are inclined to simply rely on the internet for all of their research needs (Catalano, 2013).

This study was conducted as a case study of instruction used with a small number of students within two online courses using two instructional techniques; therefore, the results are not generalisable to all library instruction. The small number of students within the second class also made it impossible to determine if there was a statistically significant difference in the final scores of students who contacted the librarian more frequently. Due to the fact that the class traditionally has a small number of students, it would not be possible to establish a control group to test fully the effect of the librarian interactions. However, this assessment project will continue in order to see if the improvements are consistently seen across time.

\section{Conclusion}

One important outcome of this project was a deeper relationship with faculty members. It is by communicating with faculty members about their students and course requirements that librarians in academic libraries are able to develop instructional methods that will reach individual students. A standard one-shot in person session would be impossible with these students, so it was necessary to find alternative ways to get the required information to the students. Connecting an appropriate instructional method to the information need allows for an individualised experience that is conductive to enhanced learning.

The joint effort of librarians with course faculty is required to ensure the development of research skills by graduate students:

While librarians are charged with imparting information literacy and information skills, it is up to the faculty teaching courses and supervising projects to ensure that students get this instruction.

(Catalano, 2013, 264) 
As seen within this project, when these two groups work together, students are developing these research skills and are better able to apply them in conducting their own research on topics in their field.

As assessment is a process of continual development, there is much that can be done both for this specific assessment project and the overall assessment of online graduate students. While this project moves forward, it would be interesting to collect more direct evidence of student learning by analysing particular assignments in more depth using a structured rubric. This could be a way to develop more granular details on the learning of the students. Overall, it is also important for librarians to take time to assess the impact that they have on online graduate students. There is a number of ways this assessment could be done as seen in the study of two student groups discussed in this paper. Libraries can have a great impact on the learning of online graduate students and by assessing that impact it is possible to bring that effect to the forefront.

\section{References}

American Library Association (2008) Standards for distance learning library services. URL: http://www.ala.org/acrl/standards/guidelinesdistancelearning [accessed 25.8.14].

Association of College and Research Libraries (2014) Assessment in action: academic libraries and student success. URL: http://www.ala.org/acrl/AiA [accessed 25.8.14].

Barrett, A. (2005) The information-seeking habits of graduate student researchers in the humanities, Journal of Academic Librarianship, 3(4), 324-331.

Blummer, B. (2009) Providing library instruction to graduate students: a review of the literature, Public Services Quarterly, 5(1), 15-39.

Blummer, B., Kenton, J. M. and Liyan, S. (2010) The design and assessment of a proposed library training unit for Education graduate students, Internet Reference Services Quarterly, 15(4), 227-242.

Blummer, B., Watulak, S. L. and Kenton, J. (2012) The research experience for Education graduate students: a phenomenographic study, Internet Reference Services Quarterly, 17(3/4), 117-146.

Catalano, A. (2010) Using ACRL standards to assess the information literacy of graduate students in an Education program, Evidence Based Library and Information Practice [online], 5(4), 21-38. URL: http://ejournals.library.ualberta.ca/index.php/EBLIP/article/view/8878 [accessed 8.3.15].

Catalano, A. (2013) Patterns of graduate students' information seeking behavior: a meta-synthesis of the literature, Journal of Documentation, 69(2), 243-274. 
Chu, S. K., and Law, N. (2007) Development of information search expertise: research students' knowledge of source types, Journal of Librarianship and Information Science, 39(1), 27-40.

Dakota State University (2015) Educational Technology, MS Ed. URL: http://catalog.dsu.edu/preview program.php?catoid=17\&poid=1202\&returnto=94 $\underline{0}$ [accessed 7.3.15].

George, C., Bright, A., Hurlbert, T., Linke, E.C., St. Clair, G. and Stein, J. (2006) Scholarly use of information: graduate students' information seeking behaviour, Information Research [online], 11(4), paper 272. URL:

http://InformationR.net/ir/11-4/paper272.html [accessed 7.3.15].

Gibbs, D., Boettcher, J., Hollingsworth, J. and Slania H. (2012) Assessing the research needs of graduate students at Georgetown University, Journal of Academic Librarianship, 38(5), 268-276.

Green, R. and Macauley, P. (2007) Doctoral students' engagement with information: an American-Australian perspective, Portal: Libraries and the Academy, 7(3), 317-332.

Hensley, M. K. and Miller, R. (2010) Listening from a distance: a survey of University of Illinois distance learners and its implications for meaningful instruction, Journal of Library Administration, 50(5/6), 670-683.

Ismail, L. (2013) Closing the gap, Reference and User Services Quarterly, 53(2), 164-173.

Kayongo, J. and Helm, C. (2010) Graduate students and the library: a survey of research practices and library use at the University of Notre Dame, Reference and User Services Quarterly, 49(4), 341-349.

Rempel, H. G., Hussong-Christian, U. and Mellinger, M. (2011) Graduate student space and service needs: a recommendation for a cross-campus solution, Journal of Academic Librarianship, 37(6), 480-487.

Shaffer, B. A. (2011) Graduate student library research skills: is online instruction effective?, Journal of Library and Information Services in Distance Learning, $\mathbf{5}(1 / 2), 35-55$.

Switzer, A. and Perdue, S.W. (2011) Dissertation 101: a research and writing intervention for Education graduate students, Education Libraries 34(1), 4-13.

Zhang, L., Watson, E.M. and Banfield, L. (2007) The efficacy of computerassisted instruction versus face-to-face instruction in academic libraries: a systematic review, Journal of Academic Librarianship, 33(4), 479-484. 


\section{Acknowledgement}

I would like to thank my team members in the Assessment in Action: Academic Libraries and Student Success project: Don Wiken, Lynette Molstad, and Carrie Ahern.

\section{Open access and copyright}

Library and Information Research is an open access journal. A freely available copy of this paper may be downloaded from the journal's website:

http://www.lirgjournal.org.uk.

Copyright and associated moral rights in works published in Library and Information Research are retained by the author(s) but this paper may be used freely, with proper attribution, in educational and other non-commercial settings. 